\title{
Application of Frequency Response Analysis for in-service power transformers
}

\author{
Dinh Anh Khoi Pham
}

\begin{abstract}
CIGRE, IEC and IEEE have recently approved the technique of Frequency Response Analysis (FRA) as an application tool for diagnosis of mechanical failures in power transformer's active part, i.e., windings, leads and the core. The diagnosis is based on the discrepancy between frequency responses measured on power transformers mainly at different time points. In Vietnam, utilities such as Power Transmission Companies and Power Corporations are investigating this technique for application on their power transformers.
\end{abstract}

Mechanical failures in power transformers cause changes on measured frequency responses starting from a medium frequency range, from several hundreds of $\mathrm{Hz}$ or tens of $\mathrm{kHz}$ depending on transformer/winding type and power. For a reliable diagnosis, the understanding of transformer/winding structure on measured frequency responses is of importance; thus, the international standards suggested the simulation approach with physical distributed transformer circuits should be exploited.

The development of physical distributed circuits of power transformers normally needs availability of internal transformer structure and material properties for an analytical approach. However, for in-service power transformers, this task is challenging since the required data are not available.

For a feasible application of the simulation based FRA interpretation, this paper introduces an investigation on the development of a distributed equivalent circuit of an in-service 6.5 MVA $47 / 27.2 \mathrm{kV}$ Yd5 power transformer. The result of this investigation is a feasible approach in determining electrical parameters in a physical distributed circuit, which supports analysis of frequency responses measured at transformer terminals for real application on in-service power transformers of utilities.

Manuscript Received on January 04th, 2017, Manuscript Revised March 27th, 2016

This research is funded by Vietnam National University HoChiMinh City (VNU-HCM) under grant number C2016-2015.

Dinh Anh Khoi Pham is with the Division of High-Voltage Engineering, Department of Power Systems, Faculty of Electrical and Electronic Engineering, Ho Chi Minh City University of Technology, Vietnam National University - Ho Chi Minh City, Vietnam (e-mail: khoipham@hcmut.edu.vn).
Index Terms - Distributed circuit, Electrical parameters, Failure diagnosis, Frequency Response Analysis, In-service power transformers.

\section{INTRODUCTION}

Cor diagnosis of mechanical failures in the $\Gamma$ active part of power transformers, i.e., the leads, windings and the core, after a suspected through-fault or during transportation, measurements of frequency responses of voltage ratio at two transformer's terminals in broad frequency range from $20 \mathrm{~Hz}$ to $2 \mathrm{MHz}$ are conducted and then compared with the corresponding ones performed when transformers were in good condition or from outer phase windings. According to the international guide and standards such as CIGRE Report [1], IEC 6007618 [2], and IEEE PC57.149TM/D9.1 [3], there are four main types of frequency responses of voltage ratio, namely, end-to-end open-circuit, end-to-end short-circuit, capacitive and inductive interwinding, which are hereafter assigned as standard frequency responses. Fig 1 shows the measurement configuration of the end-to-end open-circuit (EEOC) configuration conducted on a Yd twowinding power transformer by means of a vectornetwork-analyzer (VNA).

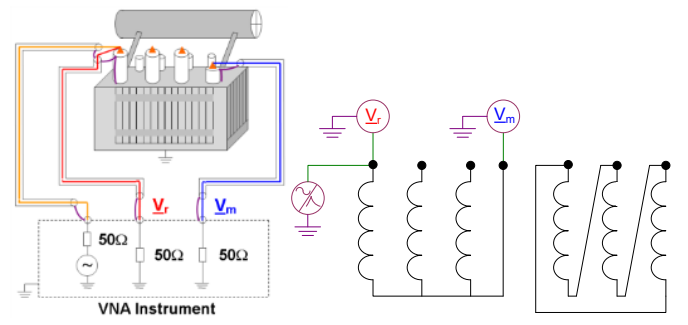

Fig 1. Standard measurement configuration of the EEOC frequency response on a Yd power transformer

The measurement procedure starts with an injection of a sinusoidal variable-frequency low- 
magnitude source ( $\mathrm{Vr}$, reference voltage) to a transformer terminal and then measurement of the induced voltage at another terminal (Vm, measured voltage). Afterwards, the magnitude and phase of the voltage ratio are determined as illustrated in Fig 2 and equations (1) and (2):

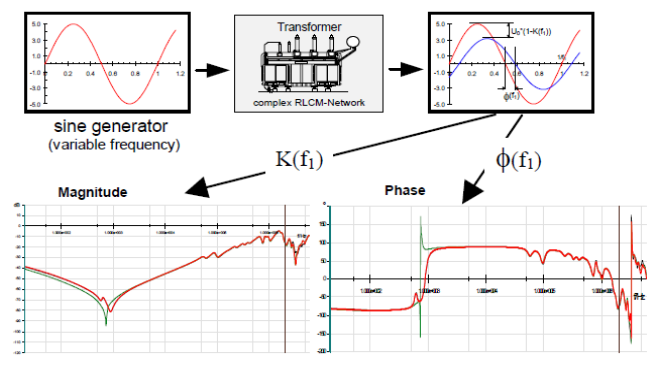

Fig 2. Measurement principle of the frequency responses of voltage ratio

$$
\begin{aligned}
& \text { Magnitude }=20 . \log _{10}\left(\left|\frac{\underline{\underline{V}}}{\underline{V}_{r}}\right|\right) \\
& \text { Phase }=\phi_{\underline{V}_{m}}-\phi_{\underline{V}_{r}}
\end{aligned}
$$

Of four standard frequency responses, the EEOC is often referred for the diagnosis since the influence of different components in transformers such as the core, windings and its interaction is shown in the measurement result (magnitude of the frequency response).

Currently, there are two general methods proposed from international/national standards for assessment of the measurement result to diagnose the transformer failures. The IEEE [3] and Chinese [4] standard suggested using the correlation coefficients between two frequency responses to evaluate the failure level in a quantitative analysis.

On the other hand, the IEC [2] and IEEE [3] proposed several patterns to detect failure types based on expert experience, including simulation in a qualitative analysis. Fig 3 introduces regions of influencing components in EEOC frequency responses of a large auto-transformer derived from simulation approach $[2,3]$. Note that the EEOC frequency responses change from transformer to transformer, thus the frequency response curves look different with different transformers and winding types.

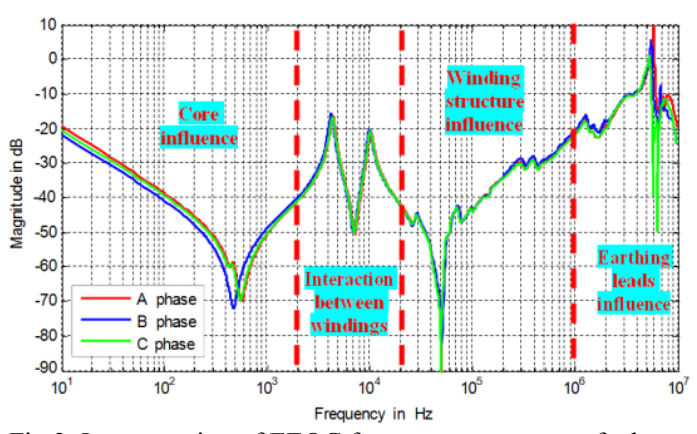

Fig 3. Interpretation of EEOC frequency responses of a large autotransformer based on simulation [3]

For an illustration of diagnosis patterns in the IEC standard [2], Fig 4 and 5 introduce failure photograph and patterns of measured frequency responses caused by a mechanical failure in large power transformers.
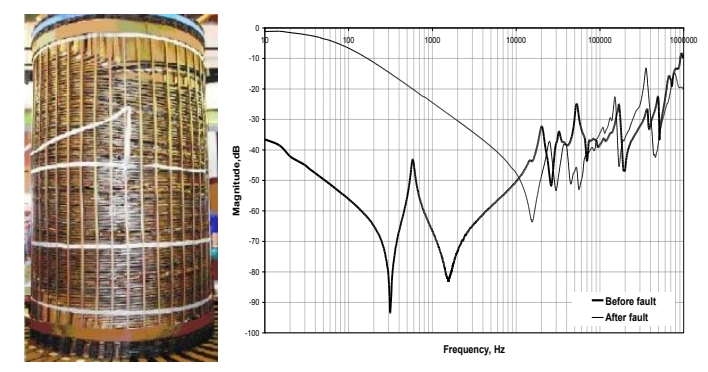

Fig 4. Photograph and frequency responses of a tap winding before and after partial axial collapse and localised inter-turn short-circuit [2]
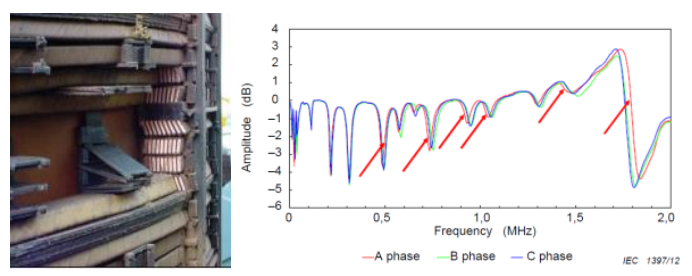

Fig 5. Photograph and per-phase frequency responses of a tap winding with conductor tilting [2]

It is observed that the failure can be easily or very difficult to detect since the discrepancies are very clear (Fig 5) or hard to recognize (Fig 6). This also means the expert experience is sometime ineffective since one cannot distinguish such a small deviation between the measured frequency responses at different transformer conditions in various frequency ranges. To restrict the uncertainty with expert experience that may happen in some situations like that in Fig 5, the author proposed a method for determination of electrical parameters associated with physical transformer circuits [5], from which the diagnosis 
is based on the change of electrical parameters, not the deviation between frequency responses. Several investigations confirmed the effectiveness of this method $[6,7]$.

To determine electrical parameters in physical transformer circuits, another kind of frequency responses, the driving-point impedances, are used. These frequency responses are different from those proposed by the international standards (voltage ratios) and therefore called as non-standard frequency responses. There are in total four configurations of the non-standard measurement, namely, the open-circuit, short-circuit, inductive and capacitive driving-point impedances. For illustration, Fig 6 shows the measurement configuration of an open-circuit driving-point impedance conducted on a phase winding of a two-winding power transformer.

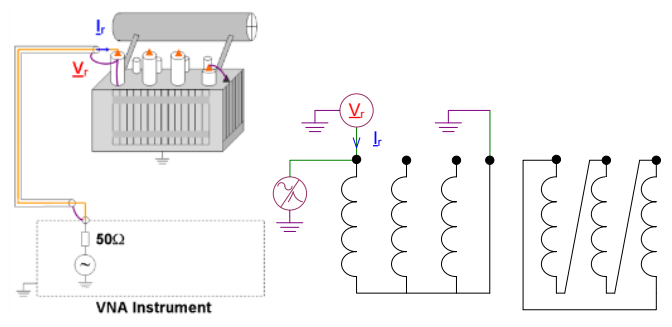

Fig 6. Non-standard measurement configuration of the opencircuit frequency response of a driving-point impedance of a Yd power transformer

Equations (3) and (4) present the calculation of magnitude and phase angle of the measured driving-point impedance in Fig 6, respectively, where the $\operatorname{Ir}$ is the terminal current flowing through the measured phase winding:

$$
\begin{aligned}
& \left|\underline{Z}_{i n}\right|=\left|\frac{\underline{V}_{r}}{\underline{I}_{r}}\right| \\
& \phi_{\underline{Z}_{i n}}=\phi_{\underline{V}_{r}}-\phi_{\underline{I}_{r}}
\end{aligned}
$$

\section{PHYSICAL EQUIVALENT CIRCUITS OF POWER TRANSFORMERS}

This section introduces two main kinds of physical transformer circuits representing physically magnetic and electrical phenomena in three-phase two-winding power transformers for the purpose of electrical parameter based interpretation of frequency responses and failure diagnosis.

\subsection{Lumped parameter circuit}

The lumped (parameter) circuit of power transformers introduced in this paper is the one derived from the duality principle for the purpose of transient and frequency response analysis [8]. Fig 7 depicts the lumped circuit of the Yd5 power transformer for illustration.

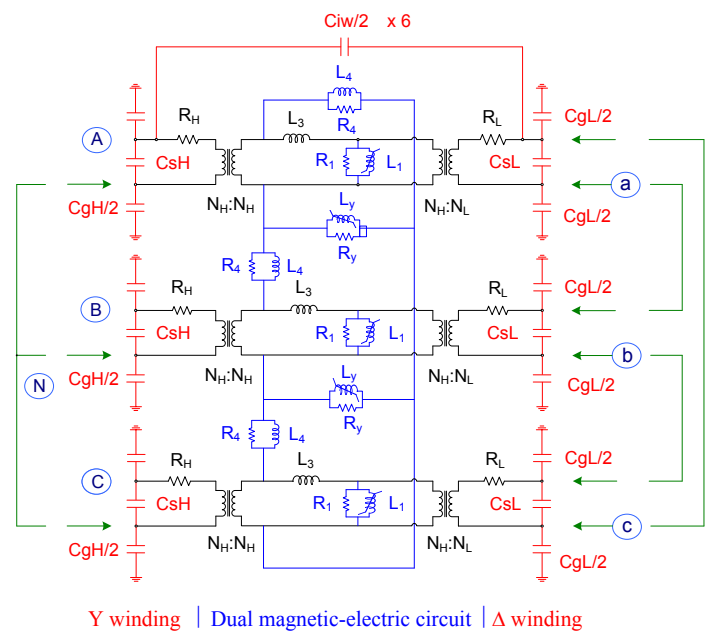

Fig 7. Lumped circuit of a Yd5 power transformer

In Fig 7, the circuit is divided into two parts: the middle part, dual magnetic-electric circuit, consists of the nonlinear core leg and yoke impedances $\left(\mathrm{R}_{1} / / \mathrm{L}_{1}, \mathrm{R}_{\mathrm{y}} / / \mathrm{L}_{\mathrm{y}}\right.$ respectively), per-phase leakage inductances $\left(\mathrm{L}_{3}\right)$, per-phase zero-sequence impedances $\left(\mathrm{R}_{4} / / \mathrm{L}_{4}\right)$; all of them are frequency dependent.

The outer part of the circuit in Fig 7 is the winding circuit representing electrical parameters of the whole winding, i.e., equivalent resistances $\left(\mathrm{R}_{\mathrm{H}}, \mathrm{R}_{\mathrm{L}}\right)$, capacitances $\left(\mathrm{C}_{\mathrm{sH}}, \mathrm{C}_{\mathrm{sL}}\right.$ : series; $\mathrm{C}_{\mathrm{gH}}, \mathrm{C}_{\mathrm{gL}}$ : ground or shunt; $\mathrm{C}_{\mathrm{iw}}$ : inter-winding), and winding connection (wye, delta) in accordance with vector group. Details of the circuit development and parameter determination procedures can be found in [5].

For circuit development, the electrical parameters in the lumped circuit can be determined based on analysis of measured frequency responses of driving-point impedances [5]. The lumped circuit then can be used for simulation approach to interpret the influence of electrical transformer parameters on measured standard frequency responses in low frequency range, e.g., from $20 \mathrm{~Hz}$ to several hundreds of $\mathrm{Hz}$ or several tens of $\mathrm{kHz}$ depending on transformer/winding type and power.

For an application, the lumped circuit is helpful 
in the determination of the series capacitances as explained later in this paper. Analysis of the lumped circuit at different transformer conditions can provide useful indicators for diagnosis of certain mechanical failures in several test transformers [6-7].

\subsection{Distributed parameter circuit}

The distributed (parameter) circuit of power transformers defined in this paper is the $n$-section lumped-parameter ladder-network [8-10], which represents physically the interaction between inductances and capacitances of part of the windings starting from medium frequencies, e.g. from several hundreds of $\mathrm{Hz}$ or several tens of $\mathrm{kHz}$. The section number $\mathrm{n}$ is selected depending on the compromise between desired accuracy and simulation complexity. Fig 8 shows a single-phase distributed circuit of a two-winding power transformer from which the complete three-phase circuit can be developed by adding the other twophase windings with an additional mutual effect between any couple of inductances.

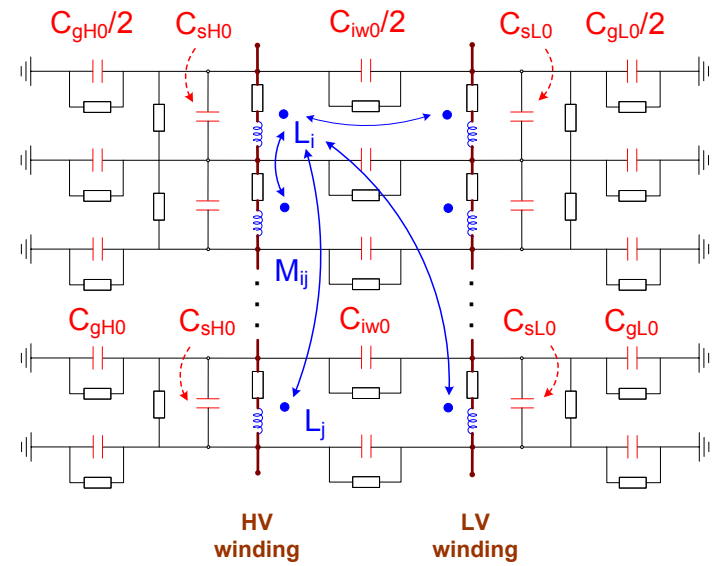

Fig 8. Single-phase distributed circuit of a two-winding power transformer

In Fig 8, the segmental self (mutual) inductances are symbolled as $\mathrm{L}_{\mathrm{i}}, \mathrm{L}_{\mathrm{j}}\left(\mathrm{M}_{\mathrm{ij}}\right)$ whereas the ground, series, inter-winding capacitances are $\mathrm{C}_{\mathrm{g} 0}, \mathrm{C}_{\mathrm{s} 0}$ and $\mathrm{C}_{\mathrm{iw} 0}$, respectively. The parallel components are corresponding resistances/conductances representing losses in core laminations, windings and insulation systems.

For circuit development, the electrical parameters in the distributed circuit could only be calculated analytically, i.e., via formulas with the availability of internal transformer structure and material properties [9-13], since the parameters represent only part of the windings. As a result, the distributed circuit has had limited application in simulation based interpretation of frequency responses measured on some specific power transformers having internal structure $[9,11,12]$. Thus the author proposes a feasible approach (mentioned later in this paper) in the determination of electrical parameters in the distributed circuit of a 6.5 MVA 47/27.2 kV Yd5 in-service power transformer for extending the application scope to black-box or in-service power transformers. For this purpose, measurements of terminal voltages according to the so-called magnetic balance test were made at $50 \mathrm{~Hz}$ by means of the device ' $\mathrm{CPC} 100$ ' and measurements of driving-point impedances (open- and short-circuit) were conducted in broad frequency range from $20 \mathrm{~Hz}$ to $2 \mathrm{MHz}$ by means of the vector-network analyzer 'FRAnalyzer'.

\section{IDENTIFICATION OF PARAMETERS IN THE LUMPED CIRCUIT OF AN IN- SERVICE POWER TRANSFORMER.}

This section presents an approach for identification of only the series capacitances in the lumped circuit of the test power transformer. The remaining electrical parameters in the lumped circuit in Fig 7 such as inductances and other capacitances etc. are already calculated based on measurement analysis [4]. The windings' series capacitance is the only one that cannot be identified from measurements since the series capacitance is a distinct property of the winding and it depends on only the winding structure, i.e., disc (ordinary/interleaved) or multi-layer type [14].

To identify the influence of the series capacitance on the total capacitive effect, a simple approach is proposed by comparing the measured open-circuit driving-point impedance (OC DPI) frequency response with the simulated one (without series capacitances in the lumped circuit) at a "capacitive" frequency point. In case there is a significant deviation between the measurement and simulation result, it is concluded that the windings' series capacitance has significant influence (on the total capacitive effect) and thus the capacitance could be identified.

Fig 9 and 10 compare the measured and simulated OC DPI frequency responses of a phase winding at $\mathrm{HV}$ and LV side, respectively, of the test transformer. It is observed from the figures that there are significant deviations between measurement and simulation at a capacitive frequency around $2 \mathrm{kHz}$, which indicates that the 
windings' series capacitances have a clear influence on the total capacitance effect (from $\mathrm{C}_{\mathrm{gH}}$ $\left.=0.629 \mathrm{nF}, \mathrm{C}_{\mathrm{gL}}=2.530 \mathrm{nF}, \mathrm{C}_{\mathrm{iw}}=2.171 \mathrm{nF}[5]\right)$.

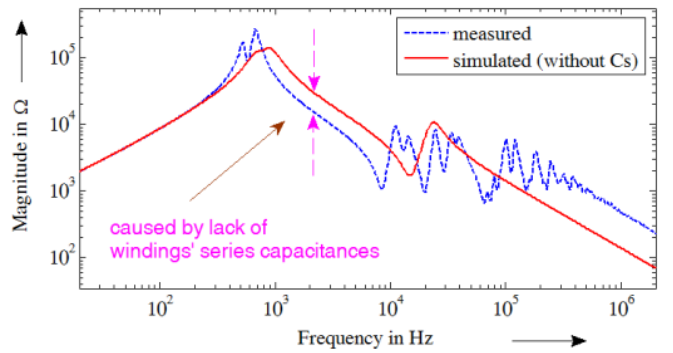

Fig 9. Measured and simulated frequency responses of the OC DPI between terminals A-N at HV side using the lumped circuit

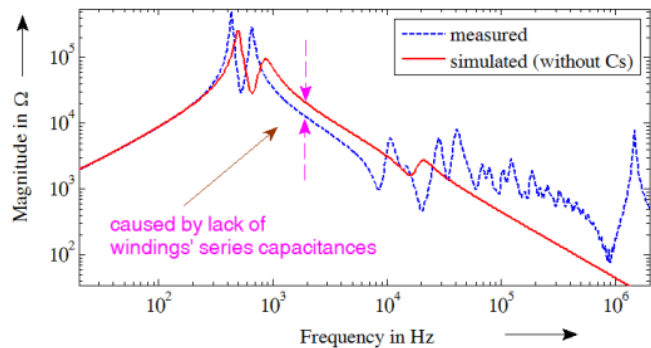

Fig10. Measured and simulated frequency responses of the OC DPI between terminals $a-b$ at LV side using the lumped circuit

The deviations become insignificant if either a value of $\mathrm{C}_{\mathrm{sH}}=1.51 \mathrm{nF}$ or $\mathrm{C}_{\mathrm{sL}}=1.44 \mathrm{nF}$ is inserted into the circuit. These values are identified separately from simulation manipulation under "trial and error" principle, which indicates that the series capacitances could not be neglected. However, there is no further information of whether which series capacitance has a dominant effect.

\section{IDENTIFICATION OF PARAMETERS IN THE DISTRIBUTED CIRCUIT OF AN IN- SERVICE POWER TRANSFORMER.}

This section introduces procedures in the determination of the main parameters in the distributed circuit, i.e., segmental inductances and capacitances, as they are key components causing resonances at medium frequencies. The conductances/resistances are of minor importance compared with inductances and capacitances since they introduce damping at resonance frequencies [9]. In fact, the conductances/resistances could not be determined from measurements and their influence on resonance damping is then investigated under "trial and error" simulation principle. However, the section starts first with the introduction of the distributed circuit of two popular winding types, the ordinary disc and multi-layer winding, since one of them can be the winding type in the test transformer.

\subsection{Distributed circuit for disc and multi-layer windings in power transformers}

Fig 11 shows the configuration and equivalent circuit in the turn-level of two discs of an ordinary disc type winding (ground and inter-winding capacitance, and mutual inductances are not shown) [10]. If the whole equivalent circuit is straightened in the longitudinal direction, it is identical with the distributed circuit in Fig 8, except the series capacitances. In Fig 12, there are two kinds of series capacitances: the one between two consecutive turns in a disc (e.g., ct between turns 1 and 2) and the other between two turns in two adjacent discs (e.g., cd between turns 1 and 20).

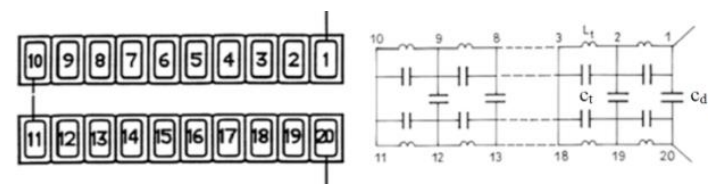

Fig 11. Configuration (a) and equivalent circuit (b) of an ordinary disc winding [10]

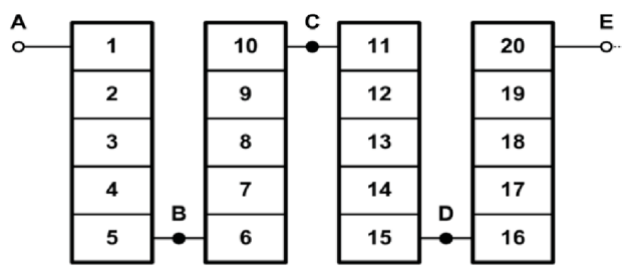

(a)

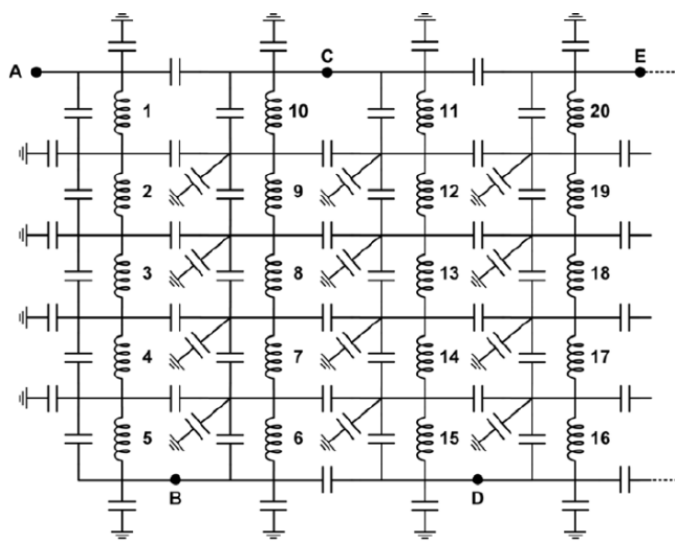

(b)

Fig 12. Configuration (a) and equivalent circuit (b) of the multilayer winding [10]

The capacitance cd could be converted into another component that is in parallel with the ct according to a principle introduced later so that the total series capacitance is their combination [15]. 
As a result, the distributed circuit in Fig 8 can be fully applied to the disc type winding.

Fig 12 shows the configuration and equivalent circuit in the turn-level of four layers of a multilayer type winding (mutual inductances are not shown) [10]. Similar to the disc winding, the multi-layer winding has two kinds of series capacitance: the turn-to-turn capacitance along a layer (e.g., ct between turns 1 and 2) and the turnto-turn capacitance between two adjacent layers (e.g., $\mathrm{cl}$ between turns 1 and 10).

For an acceptable solution with simulation, the number of circuit sections per layer and the layer number would be large enough. In fact, one does not know these numbers for in-service power transformers and thus an equivalent transformation is necessary to convert the multi-layer winding circuit into the disc circuit. Fig 13 illustrates the transformation of the series capacitances $\left(c_{t}\right.$ and $\left.c_{l}\right)$ under the assumption that there exist equipotential surfaces between layers (or discs with the disc type winding) [12, 15].

In Fig 13, the $\mathrm{c}_{1}$ between two layers is considered as two $\left(2 \mathrm{c}_{1}\right)$ connected in series. With the equipotential surfaces between layers, the $\left(2 c_{1}\right)$ between adjacent layers can be broken and connected with that of the same layer to form the component $c_{1}$ in parallel with $c_{t}$. As a result, the concept of total series capacitance is derived, from which the equivalent disc type winding circuit shown in Fig 8 is derived from the multi-layer winding circuit.

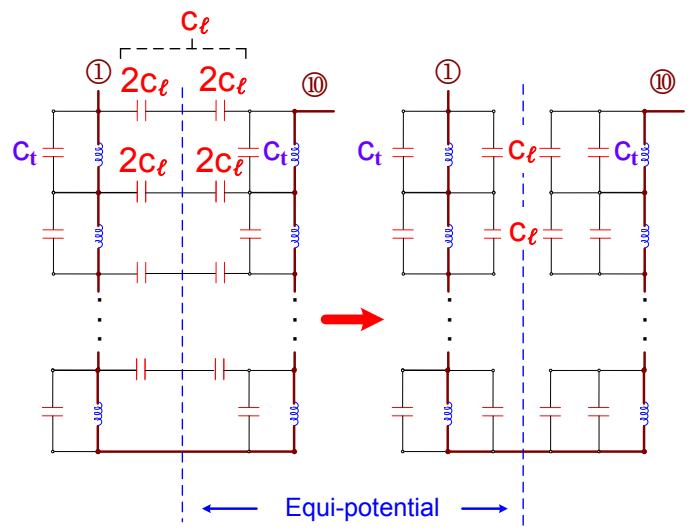

Fig 13. Equivalent transformation of the multi-layer winding circuit into the disc winding circuit

\subsection{Determination of segmental capacitances in the distributed circuit}

As the distributed circuit in Fig 8 can be applied for both disc and multi-layer type winding, there is only one variable involved with the simulation: the section number $\mathrm{n}$. Since the windings in the test transformer are divided into identical sections, the capacitances could be calculated using a simple relation:

$$
\mathrm{C}_{\mathrm{gH} 0}=\mathrm{C}_{\mathrm{gH}} / \mathrm{n} ; \mathrm{C}_{\mathrm{gL} 0}=\mathrm{C}_{\mathrm{gL}} / \mathrm{n} ; \mathrm{C}_{\mathrm{iw} 0}=\mathrm{C}_{\mathrm{iw}} / \mathrm{n}
$$

where the per-phase capacitances $\mathrm{C}_{\mathrm{gH}}, \mathrm{C}_{\mathrm{gL}}$, and $\mathrm{C}_{\mathrm{iw}}$ are determined from measurements. The capacitances are considered reasonably as constants since the permittivity of transformer insulation materials does not change much in the analyzed frequency range.

As a result, the internal structure of the test transformer and dielectric properties of insulation systems are not required since the analytical calculation of the capacitances is not necessary.

\subsection{Determination of self and mutual inductances in the distributed circuit}

There are in total 30 components of self/mutual inductances of/between sections at different phases, i.e., phase A, B or C, and different sides, i.e., HV or LV side. For instance, one winding section of phase A at $\mathrm{HV}$ side has its own self inductance $\left(\mathrm{L}^{\mathrm{A}}\right)$ and a mutual inductance with another section at this phase $\left(\mathrm{M}^{\mathrm{AA}}\right)$, or other phase/side $\left(\mathrm{M}^{\mathrm{AB}}\right.$ or $\mathrm{M}^{\mathrm{AC}}$ at $\mathrm{HV}$ side; $\mathrm{M}^{\mathrm{Aa}}, \mathrm{M}^{\mathrm{Ab}}$, or $\mathrm{M}^{\mathrm{Ac}}$ at LV side). However, due to the symmetry between windings at outer phase, there are only 12 different inductance components or matrixes (when the transformer is in good condition).

The parameter determination procedure starts with the identification of self and mutual inductances of two sections on the same phase winding, i.e., $\mathrm{A}, \mathrm{B}$ or $\mathrm{C}$, at low frequencies by analysis of the per-phase open-circuit driving-point impedances (OC DPIs). For transformers with starstar winding connection, there is only mutual effect between winding sections in the excited phase winding. Then voltage-current relation at the transformer terminal of the n-section excited winding of phase A (assumed at HV side) can be expressed as:

$$
\mathrm{U}_{\mathrm{A}}{ }^{\mathrm{oc}}=\mathrm{I}_{\mathrm{A}}{ }^{\mathrm{oc}} \cdot \mathrm{n} \cdot \mathrm{X}^{\mathrm{A}}+\mathrm{I}_{\mathrm{A}}{ }^{\mathrm{oc}} \cdot \mathrm{n} \cdot(\mathrm{n}-1) \cdot \mathrm{X}^{\mathrm{AA}}
$$

where $\mathrm{U}_{\mathrm{A}}{ }^{\text {oc }}$ and $\mathrm{I}_{\mathrm{A}}{ }^{\mathrm{oc}}$ are r.m.s value of the applied open-circuit single phase voltage and corresponding current on the winding of phase A; $\mathrm{X}^{\mathrm{A}}=\omega \cdot \mathrm{L}^{\mathrm{A}}$ and $\mathrm{X}^{\mathrm{AA}}=\omega \cdot \mathrm{M}^{\mathrm{AA}}$ are self and mutual reactance, respectively, at low frequencies where the measured OC DPI is purely inductive.

For acceptable analysis feasibility, the self and mutual reactance/inductance are approximate: $\mathrm{X}^{\mathrm{A}}$ $\approx \mathrm{X}^{\mathrm{AA}}$, then equation $(6)$ can be simplified into:

$$
\mathrm{X}^{\mathrm{A}}=\mathrm{X}_{\mathrm{A}}{ }^{\mathrm{oc}} / \mathrm{n}^{2}
$$


where $\mathrm{X}_{\mathrm{A}}{ }^{\mathrm{oc}}=\mathrm{U}_{\mathrm{A}}{ }^{\mathrm{oc}} / \mathrm{I}_{\mathrm{A}}{ }^{\mathrm{oc}}$ is the open-circuit driving-point reactance of the winding of phase $A$. By this manner, the self and mutual inductances of winding sections of phase $\mathrm{B}$ and $\mathrm{C}$ can be calculated.

The equations (6) and (7) are still applicable for star-delta winding connection of the test transformer since the mutual elimination effect in the delta winding will take place due to positive mutual inductance $\mathrm{M}^{\mathrm{Aa}}$ and negative mutual inductances $\mathrm{M}^{\mathrm{Ab}}$ and $\mathrm{M}^{\mathrm{Ac}}$.

The next step of the parameter determination procedure is to determine the mutual inductances between sections of phase windings in different phases at low frequencies. This procedure is based on analysis of the magnetic balance test by supplying an $\mathrm{AC}$ voltage to a terminal (at a low frequency) when all other terminals are left floating and then measuring the voltages at these terminals. The ratios between the induced voltages at terminals of the non-tested phase windings, e.g., $\mathrm{B}$ or $\mathrm{C}$, and the supplied voltage on the tested perphase winding, i.e., A, provide factors for calculating mutual inductances $\mathrm{M}^{\mathrm{AB}}$ and $\mathrm{M}^{\mathrm{AC}}$ from $\mathrm{L}^{\mathrm{A}}$ (for star-star winding connection). Similar to the first case, the influence of the other winding at the other side, i.e., LV, regardless of its connection (star or delta) could be neglected.

Afterward, the mutual inductances between inter-winding sections of different phases such as $\mathrm{M}^{\mathrm{Ab}}, \mathrm{M}^{\mathrm{Ac}}$ could be obtained from $\mathrm{M}^{\mathrm{AB}}$ and $\mathrm{M}^{\mathrm{AC}}$ since they are proportional to the transformer ratio.

The next step of the parameter procedure is to determine mutual inductances between $\mathrm{HV}$ and LV winding sections at low frequencies by analysis of per-phase short-circuit driving-point impedances (SC DPIs) at low frequencies. In the short-circuit tests, for instance, the winding of phase $\mathrm{A}$ at one side (HV) is excited whereas the other phase winding at the other side (LV) is shortcircuited, which yields the below relationship for star-star winding connection:

$$
\mathrm{U}_{\mathrm{A}}{ }^{\mathrm{sc}}=\mathrm{I}_{\mathrm{A}}{ }^{\mathrm{sc}} \cdot \mathrm{n}^{2} \cdot \mathrm{X}^{\mathrm{A}}+\mathrm{I}_{\mathrm{a}}^{\mathrm{sc}} \cdot \mathrm{n}^{2} \cdot \mathrm{X}^{\mathrm{Aa}}
$$

where $\mathrm{U}_{\mathrm{A}}{ }^{\mathrm{sc}}, \mathrm{I}_{\mathrm{A}}{ }^{\mathrm{sc}}$ and $\mathrm{I}_{\mathrm{a}}{ }^{\mathrm{sc}}$ are r.m.s value of the applied single phase voltage, HV and LV shortcircuit currents, respectively, on the windings of phase $A ; X^{\mathrm{Aa}}=\omega \cdot \mathrm{M}^{\mathrm{Aa}}$ is mutual reactance at low frequencies where the measured SC DPI is purest inductive.

The short-circuit current flowing in the LV winding of phase $A\left(\mathrm{I}_{\mathrm{a}}^{\mathrm{sc}}\right)$ has the r.m.s value proportional to that of the current flowing within the $\mathrm{HV}$ phase winding $\left(\mathrm{I}_{\mathrm{A}}^{\mathrm{sc}}\right)$ with the transformer ratio ki, which means:

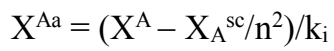

where $X_{A}{ }_{A}^{s c}=U_{A}{ }^{s c} / I_{A}{ }^{s c}$ is the short circuit driving-point reactance of the winding of phase $\mathrm{A}$ and $\mathrm{k}_{\mathrm{i}} \approx \mathrm{I}_{\mathrm{a}}{ }^{\mathrm{sc}} / \mathrm{I}_{\mathrm{A}}{ }^{\mathrm{sc}}$.

The aforementioned steps can be applied for analysis of measurements of OC and SC DPIs of the LV delta winding to identify self and mutual of $\mathrm{LV}$ phase winding sections, i.e., $\mathrm{L}^{\mathrm{a}}, \mathrm{L}^{\mathrm{b}}, \mathrm{L}^{\mathrm{c}}$ and $\mathrm{M}^{\mathrm{Aa}}, \mathrm{M}^{\mathrm{Bb}}, \mathrm{M}^{\mathrm{Cc}}$ at low frequencies.

The remaining of the analysis task is to identify the calculated self and mutual inductances at medium frequencies since the inductances decrease with increasing frequency following kind of pattern introduced in [13]. This could be reasonably achieved by analysis the SC DPIs since their inductive range is larger than that of the OC DPIs. Note that the inductances are determined from measurements that reflect the saturation condition of the transformer core.

\section{RESULTS.}

Simulation of the 16-section distributed circuit without windings' series capacitances in the configuration of OC DPIs also shows a significant deviation compared with the measurement at frequency of $2 \mathrm{kHz}$. However, values of the capacitances are slightly different compared with those determined using the lumped circuit $\left(\mathrm{C}_{\mathrm{sH}}=\right.$ $1.81 \mathrm{nF}$ or $\mathrm{C}_{\mathrm{sL}}=2.02 \mathrm{nF}$ ) to compensate the deviations.

In addition, the distributed circuit shows its advantage in the simulation of resonances at medium frequencies against the lumped circuit. Fig 14, 15 and 16 present comparisons between measurement and simulation results, which are conducted at low frequencies (LF) and medium frequencies with only $\mathrm{C}_{\mathrm{sH}}, \mathrm{C}_{\mathrm{sL}}$ or an equal combination of $\mathrm{C}_{\mathrm{sH}}$ and $\mathrm{C}_{\mathrm{sL}}$, respectively.

The agreements between measurement and simulations at low frequencies (in the range of tens and hundreds of $\mathrm{Hz}$ ) in the figures indicate that the inductances calculated using the proposed approach in section 4.3 are acceptable. This is valuable since normally the segmental inductances in the distributed circuit should be calculated analytically using internal transformer structure and magnetic-electrical properties of the core. 


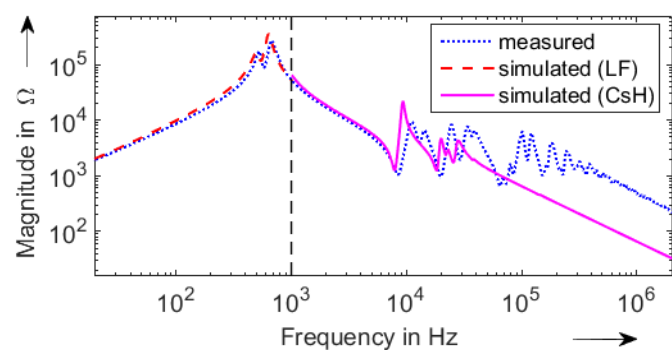

Fig 14. Measured and simulated frequency responses of OC DPI between terminals A-N at HV side using the distributed circuit $(\mathrm{CsH}=1.81 \mathrm{nF})$

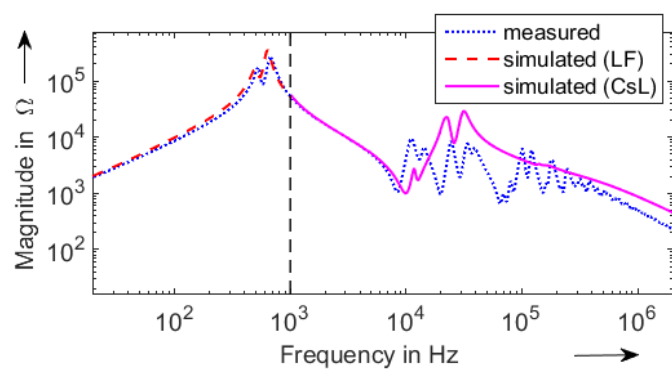

Fig 15. Measured and simulated frequency responses of OC DPI between terminals A-N at HV side using the distributed circuit $(\mathrm{CsL}=2.02 \mathrm{nF})$

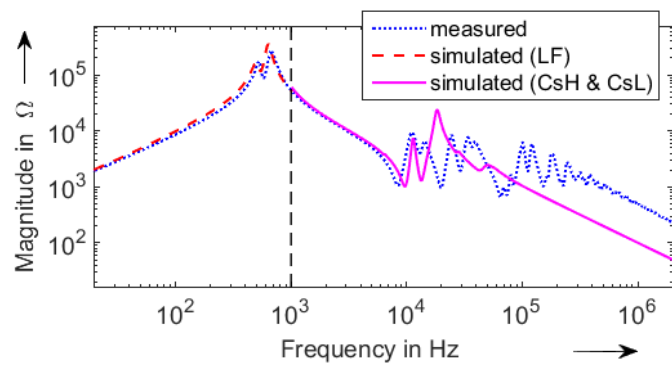

Fig 16. Measured and simulated frequency responses of OC DPI between terminals A-N at $\mathrm{HV}$ side using the distributed circuit $(\mathrm{CsH}=0.905 \mathrm{nF}$ and $\mathrm{CsL}=1.01 \mathrm{nF})$

In addition, it is realized that the shape of multiresonances from measurement at around $10 \mathrm{kHz}$ seems to match with that from simulation in Fig 14 , but the overall shape of multi-resonances from measurement in the range from 10 to $70 \mathrm{kHz}$ seems to agree with that from simulation in Fig 15. This suggests the selected section number of the distributed circuit should be larger for the conclusion of whether the HV or LV winding has the dominant effect of series capacitance (equal effect seems not to be a case as shown in Fig 16), which can be conducted using the so-called statespace modeling technique.

Simulation of the 16-section distributed circuit in the configuration of OC DPIs at LV side also shows the same result and therefore will not be introduced.

\section{CONCLUSION}

This paper proposes approaches in determination of electrical parameters in a physical distributed circuit of an in-service power transformer, which has not been solved completely in any publication so far. The introduced approaches should be combined with others proposed from [5-8] to analyze comprehensively electrical parameters on the distributed transformer circuit. Consequently, the practical application of this circuit on simulation based interpretation of frequency responses measured on in-service power transformers at low and medium frequencies could be feasible for the diagnosis.

\section{REFERENCES}

[1]. CIGRE Report 342 W.G. A2.26, Mechanical-condition assessment of transformer windings using FRA, 2008.

[2]. IEC 60076-18, Power transformers - Part 18: Measurement of frequency response, 2012.

[3]. IEEE PC57.149TM/D9.1, Draft guide for the application and interpretation of frequency response analysis for oil immersed transformers, Mar. 2012.

[4]. DT/T-2004 Chinese standard, Frequency response analysis on winding deformation of power transformers, 2005.

[5]. D.A.K. Pham, T.M.T. Pham, H. Borsi and E. Gockenbach, A new method for purposes of failure diagnostics and FRA interpretation applicable to power transformers, IEEE Trans. Dielectr. and Electr. Insul., vol. 20, no. 6, pp 2026-2034, 2013.

[6]. D.A.K. Pham, T.M.T. Pham, H. Borsi and E. Gockenbach, A new diagnostic method to support standard FRA assessments for diagnostics of transformer winding mechanical failures, IEEE Electr. Insul. Mag., vol. 30, no. 2, pp. 34-41, 2014.

[7]. D.A.K. Pham, T.M.T. Pham, H. Borsi and E. Gockenbach, Application of a new method in detecting a mechanical failure associated with series capacitance change in a power transformer winding, IEEE Int. Conf. Liquid Dielectr., Slovenia, 2014.

[8]. D.A.K. Pham, E. Gockenbach, Analysis of Physical Transformer Circuits for Frequency Response Interpretation and Mechanical Failure Diagnosis, IEEE Trans. on Dielectrics and Electrical Insulation, vol. 23, issue 3, pp. 1491-1499, June 2016.

[9]. Wang Z., Li J., and Sofian D. M., Interpretation of transformer FRA responses-Part I: Influence of winding structure, IEEE Trans. Pow. Del., vol. 24, no. 2, pp. 703710, 2009.

[10]. Su C. Q., Electromagnetic transients in transformer and rotating machine windings, Information Science Reference, IGI Global, 2013.

[11]. Rahimpour E., Christian J., Feser K., and Mohseni H., Transfer function method to diagnose axial displacement and radial deformation of transformer windings, IEEE Trans. Pow. Del., vol. 18, no. 2, pp. 493-505, 2003. 
[12]. Abeywickrama N., Serdyuk Y. V., and Gubanski S. M., High-Frequency Modeling of Power Transformers for Use in Frequency Response Analysis, IEEE Trans. Pow. Del., vol. 23, no. 4, pp. 2042-2049, 2008.

[13]. Wilcox D. J., Hurley W. G., and Conlon M., Calculation of self and mutual impedances between sections of transformer windings, IEE Proceed., vol. 1365, no. 5, pp 308-314, 1989.

[14]. Harlow, J., Electric power transformer engineering, CRC Press, 2007.

[15]. Popov M., Smeets R.P.P., Van der Sluis L., De Herdt H. and Declercq J., Analysis of Voltage Distribution in Transformer Windings During Circuit Breaker Prestrike, Int. Conf. on Power Systems Transients (IPST2009), Kyoto, Japan June 3-6, 2009.

Dinh Anh Khoi Pham was born in Ninh-Thuan, Vietnam, in 1979. He received the B.Sc. and M.Sc. in electrical engineering from the Ho Chi Minh City University of Technology (HCMUT) in 2002 and 2004, respectively, and the Ph.D. degree in electrical engineering from the Leibniz Universität Hanover, Germany in 2013. During 2002-2008 and since 2013, he has worked as Lecturer at the Ho Chi Minh City University of Technology, Vietnam National University - Ho Chi Minh City, Vietnam. His research interest includes simulation, testing and diagnostics of power transformers.

\title{
Úng dụng kỹ thuật phân tích đáp ứng tần số cho máy biến áp lực đang vận hành
}

\author{
Pham Đình Anh Khôi
}

Trường Đại học Bách Khoa, Đại học Quốc gia Tp. Hồ Chí Minh.

Tóm tắt - CIGRE, IEC và IEEE gần đây đã đề xuất áp dụng kỹ thuật Phân tích đáp ứng tần số (FRA) để chẩn đoán sự cố cơ trong phần tích cực của máy biến áp lực (MBA) bao gồm các cuộn dây, đầu nối và lõi thép. Việc chẩn đoán dựa trên sự sai lệch của các đáp ứng tần số đo lường chủ yếu vào các thời điểm khác nhau. Ở Việt Nam hiện nay, các công ty điện lực như Tổng công ty truyền tải điện và Tổng công ty phân phối điện đang khảo sát ứng dụng kỹ thuật này cho các MBA trên lưới.

Các sự cố cơ trong MBA gây ra sự thay đổi trên các đáp ứng tần số đo lường bắt đầu từ vùng tần số trung bình, từ vài trăm $\mathrm{Hz}$ đến hàng chục $\mathrm{kHz}$ phụ thuộc vào công suất $\mathrm{MBA}$ và kiểu quấn các cuộn dây. Để việc chẩn đoán có hiệu quả, hiểu biết về cấu trúc của MBA / cuộn dây lên dạng các đáp ứng tần số là rất quan trọng; vì vậy các tiêu chuẩn quốc tế đã đề xuất nên thực hiện mô phỏng trên các mạch tương đương vật lý thông số phân bố của MBA.

Việc xây dựng các sơ đồ mạch tương đương này thông thường cần thông số cấu trúc bên trong MBA và các đặc tính vật liệu để tính toán giải tích. Tuy nhiên, việc tính toán này đối với các MBA đang vận hành là rất khó khăn do các dữ liệu bên trong MBA không có sẵn.

Để có thể ứng dụng kỹ thuật FRA dựa trên mô phỏng, bài báo giới thiệu một nghiên cứu khảo sát xây dựng mạch tương đương thổng số phân bố của một MBA đang vận hành 6.5 MVA 47/27.2 kV Yd5. Kết quả của nghiên cứu là một giải pháp khả thi xác định các thông số điện trong mạch tương đương $\mathrm{MBA}$, góp phần phân tích đáp ứng tần số dựa trên mô phỏng cho các MBA đang vận hành của các công ty điện lực.

Từ khóa - Mạch thông số phân bố, thông số điện, chẩn đoán sự cố, phân tích đáp ứng tần số, máy biến áp đang vận hành. 